\title{
Associations of sleep characteristics with atopic disease: a cross-sectional study among Chinese adolescents
}

\author{
Yiting Chen ${ }^{1}$, Qian Yang ${ }^{1}$, Kena Zhao ${ }^{1}$, Zengqiang $\mathrm{Wu}^{3}$, Xiaoming Shen ${ }^{2}$ and Shenghui $\mathrm{Li}^{1,2^{*}}$ (1)
}

\begin{abstract}
Background: Adolescence, as a transition between childhood and adulthood, is a critical stage for the longterm control of atopic diseases. We aim to determine if sleep characteristics are involved in the increased risk of atopic disease among adolescents.

Methods: Adopting the stratified cluster random sampling method, this cross-sectional survey included 4932 participants aged 12-18 years. The Chinese version of adolescent sleep disturbance questionnaire and the adolescent sleep hygiene scale were used to collect information on sleep problems and sleep hygiene, respectively. Logistic regression models were implemented to examine the associations of sleep with atopic diseases.

Results: Sleep duration was not found to be related with allergic diseases. By contrast, sleep-disordered breathing was associated with an increased risk of asthma (adjusted $\mathrm{OR}=1.79,95 \% \mathrm{Cl} 1.25-2.55$ ), allergic rhinitis (adjusted $\mathrm{OR}=1.95,95 \% \mathrm{Cl} 1.52-2.49$ ), and eczema (adjusted $\mathrm{OR}=1.63,95 \% \mathrm{Cl} 1.23-2.16$ ); poor sleep physiology was correspondent to increased odds of asthma (adjusted $\mathrm{OR}=1.69,95 \% \mathrm{Cl} 1.24-2.29$ ), allergic rhinitis (adjusted $\mathrm{OR}=1.40,95 \% \mathrm{Cl} 1.13-1.73$ ) and eczema (adjusted $\mathrm{OR}=1.66,95 \% \mathrm{Cl} 1.32-2.09$ ); non-optimal sleep environment was associated with an increased prevalence of asthma (adjusted $\mathrm{OR}=1.52,95 \% \mathrm{Cl} 1.08-2.12$ ), allergic rhinitis (adjusted $\mathrm{OR}=1.32,95 \% \mathrm{Cl} 1.04-1.69$ ) and eczema (adjusted $\mathrm{OR}=1.53,95 \% \mathrm{Cl} 1.19-1.96)$.

Conclusions: As sleep-disordered breathing, poor sleep physiology and non-optimal sleep environment were associated with a higher risk of allergic diseases, the results of this study provide a new concept for the adjuvant treatment of allergic diseases in adolescents. Management strategies of allergic diseases should take regular screening and targeted treatment of sleep issues into account.
\end{abstract}

Keywords: Sleep, Asthma, Allergic rhinitis, Eczema, Adolescents

\section{Background}

The increasing prevalence of allergic diseases has aroused great public concern in the world [1]. In Shanghai, the prevalence of children's allergic diseases has increased exponentially in recent decades, predisposing Shanghai

\footnotetext{
*Correspondence: Ish9907@163.com; submission9907@163.com

${ }^{1}$ School of Public Health, Shanghai Jiao Tong University School

of Medicine, 227 South Chongqing Road, Huangpu District,

Shanghai 200025, China

Full list of author information is available at the end of the article
}

to the city of the highest prevalence of allergic diseases in China [2]. It is generally believed that allergic diseases are prevalent mainly in childhood [3]. Studies have shown that allergic diseases usually occur in early childhood, and can persist into adulthood if not controlled promptly $[4,5]$. Adolescence is the transitional period between childhood and adulthood. If effective control is carried out at puberty, potential risk factors and a sturdy immune system might work together in a positive way, thus controlling the allergic diseases without recurrence.

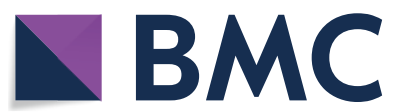

(c) The Author(s) 2021. This article is licensed under a Creative Commons Attribution 4.0 International License, which permits use, sharing, adaptation, distribution and reproduction in any medium or format, as long as you give appropriate credit to the original author(s) and the source, provide a link to the Creative Commons licence, and indicate if changes were made. The images or other third party material in this article are included in the article's Creative Commons licence, unless indicated otherwise in a credit line to the material. If material is not included in the article's Creative Commons licence and your intended use is not permitted by statutory regulation or exceeds the permitted use, you will need to obtain permission directly from the copyright holder. To view a copy of this licence, visit http://creativeco mmons.org/licenses/by/4.0/. The Creative Commons Public Domain Dedication waiver (http://creativecommons.org/publicdomain/ zero/1.0/) applies to the data made available in this article, unless otherwise stated in a credit line to the data. 
However, to date, very limited data are available regarding allergic diseases in adolescence $[6,7]$.

Even though sleep plays an important role in daily functioning, a high prevalence of sleep problems has been reported in adolescence [8,9]. Accumulating evidence suggested that sleep was implicated in metabolism and immune regulation [10-13]. Recently, new evidence has further suggested that disturbed sleep and atopic disorders are intrinsically linked in pathophysiological processes [14].

A previous cross-sectional study has indicated that sleep duration $<7.8 \mathrm{~h}$ per night was associated with the higher odds of food and aeroallergens sensitization in rural Chinese adolescents [15]. Longitudinal studies further suggest that sleep problems, e.g., being overtired, sleep-disordered breathing, and persistent frequent nocturnal waking, were associated with higher risks of allergic rhinitis or asthma in western adolescents, however, it does not result in higher odds of eczema [16]. A prospective observational study conducted in Ohio, USA suggested that sleep-disordered breathing can be a modifiable risk factor for severe asthma, revealing that asthma symptoms could be improved by treating SDB [17]. Although these findings indicated a potential link between sleep and allergic diseases, evidence on adolescence is still scarce. Furthermore, most of the existing studies have assessed only a subset of sleep dimensions, such as sleep duration, sleep problems, or a specific allergic disease. So far as we know, the relationship between all-round sleep features and atopic diseases has not yet been identified. To fill this gap, our research systematically expounded on sleep problems, sleep hygiene, and sleep duration, covering comprehensive aspects of sleep features. Moreover, this study included three major allergic diseases prevalent in adolescents, asthma, allergic rhinitis, and eczema. Finally, sleep patterns on weekdays and weekends were analyzed separately as different school schedules and socioeconomic factors may lead to divergent sleep characteristics among Chinese adolescents and those in Western countries [18].

To the best of our knowledge, this is the first cross-sectional study evaluating the associations of comprehensive sleep characteristics, herein sleep problems, sleep hygiene, and sleep duration, with asthma, allergic rhinitis, and eczema among adolescents.

\section{Methods}

\section{Study participants and protocol}

The present study, based on a cross-sectional survey, was conducted in Shanghai in November 2009. Detailed information on participant recruitment was described previously [19]. Briefly, among 9 urban areas and
8 suburban/rural areas in Shanghai, 4 urban areas and 2 suburb/rural areas were randomly sampled. Subsequently, 2 junior high schools and 2 senior high schools were randomly selected in each area. Overall, 5159 students were eligible for this study. Among them, 96.25\% completed the questionnaires. The final sample consisted of 4932 participants after deleting the missing data on targeted allergic diseases.

The survey was conducted in health education classes. The purpose of the survey and guidance on questionnaires were explained to teachers and students, and the principle of voluntary participation was accentuated. Students were asked to finish the questionnaire anonymously, absent students were not counted towards the total.

\section{Sleep variables \\ Sleep duration}

Sleep habit was evaluated by standardized questionnaires. Given the fact that students' sleep condition on weekends may be differentiated from that on weekdays. Weekday (Monday to Friday) and weekend (Saturday and Sunday) bedtime, wake-up time, and sleep latency time were asked separately, and sleep duration during weekdays and weekends were calculated, respectively [15]. Night-time sleep duration was calculated based on the time a child usually goes to bed at night and wakes up in the morning, which was found to be normally distributed.

\section{Sleep problem}

The Chinese version of the adolescent sleep disturbance questionnaire (ASDQ) is a 26-item instrument to assess sleep problems of adolescents aged 12-18 years [20]. The ASDQ has been approved to be a qualified instrument for assessing sleep problems among Chinese adolescent in our previous study (Cronbach's alpha coefficients for the internal consistency were 0.71 for the overall questionnaire and ranged from 0.61 to 0.73 for subscales; intraclass correlation coefficients for the test-retest reliability were 0.85 for the overall questionnaire and ranged from 0.64 to 0.82 for subscales) $[21,22]$. The 26 items were conceptually grouped into 6 subscales: difficulty in falling asleep (5 items), difficulty in maintaining sleep (7 items), difficulty in reinitializing sleep (5 items), difficulty in returning to wakefulness (3 items), sleep-disordered breathing (3 items) and disorders of arousal (3 items). The participants reported how often these sleep behaviors in each item occurred in the last month, and a 5-point Likert-type scale ( $4=$ always, $0=$ never) was adopted. In each subscale, if any sleep problem occurred once per week or more frequently, we defined that the participant suffered from the corresponding sleep problem. Each subscale score 
was encoded into two categories: "1" indicating the presence of such sleep problems, and " 0 " indicating the absence of such sleep problems.

\section{Sleep hygiene}

The adolescent sleep hygiene scale (ASHS) was adopted to assess sleep hygiene among adolescents [23]. Based on the literature review [24], the ASHS was modified in terms of the current needs. There were 24 items in the modified Chinese version of ASHS (M-ASHS). These are divided into six subgroups by different contents, including sleep physiology, sleep cognition, sleep emotion, sleep environment, and sleep stability, which has been reported in the previous study [22, 25]. 5 -point Likert-type scale was implemented $(1=$ always, $5=$ never), that a higher score indicates a higher potential of sleep hygiene situation. M-ASHS for the Chinese version had been validated, showing a strong reliability (for the overall questionnaire, Cronbach's alpha coefficients for the internal consistency were 0.89 and intraclass correlation coefficients for the test-retest reliability were 0.85 . For subscales, internal consistency ranged from 0.88 to 0.91 , and intraclass correlation coefficients for the test-retest reliability ranged from 0.60 to 0.88$)[22,25]$. In each dimension, if one or more sleep behavior occurred once per week or more frequently, we defined that the participant was stuck in poor sleep hygiene. To evaluate the impact of sleep hygiene on atopic diseases, each subscale score was recoded into two categories: "0" for good sleep hygiene, and "1" for poor sleep hygiene.

\section{Ascertainment of allergic diseases}

Self-reported yes-no questions were applied to evaluate atopic diseases, including asthma, allergic rhinitis, and eczema. The prevalence of asthma, allergic rhinitis, and eczema were based on the participants' responses to the following three questions: "Have you been diagnosed with asthma/allergic rhinitis/eczema by clinical specialists?".

\section{Covariates variables}

We also collected participants' information on possible confounding factors based on the literature [25].

1. Demographic characteristics consist of the age and gender of the participants. Family structures were divided into single-parent families, nuclear families, and extended families; socioeconomic status include the average personal monthly household income and educational levels of parents.

2. Maternal and perinatal characteristics included delivery mode, feeding pattern, mother's smoking exposure during gestation, mother's drinking status during gestation, mother's sleep condition during gestation, mother's age at delivery, and father's age at delivery.

3. Biological chronic health problems and activity routine behaviors included overweight/obesity, smoking exposure, drinking status, physical activity, respectively on weekdays and weekends.

\section{Statistical analysis}

The percentage for categorical variables was reported in statistical descriptions. Logistic regression was applied to compare demographic factors between normal and allergic disease groups. Additionally, multivariate logistic regression was implemented to estimate the adjusted associations of sleep problems, sleep hygiene, sleep duration, and three allergic diseases. With " 1 " for adolescents having a certain kind of allergic disease and " 0 " for adolescents without any of the three allergic diseases. Adjustments were made following a threestep procedure. First, simply adjusted for demographic characteristics, family structure, and socioeconomic status (Adjusted model 1). Second, based on Adjusted model 1, conditions of gestation, delivery, and feeding were further adjusted (Adjusted model 2). Finally, based on the prior two adjusted models, adolescent's health problems, daily activity routines were further adjusted (Adjusted model 3). Spearman correlation analysis was used to examine the correlation between sleep parameters and different atopic diseases. The Benjamini and Hochberg false discovery rate method was adopted for multiple testing corrections [26].

All analyses were performed with the Statistical Package for the Social Sciences version 24 (SPSS Inc, Chicago, IL, USA) and the p.adjust package for $\mathrm{R}$ statistical software (version 3.5.1). The significance level was set at $\mathrm{p}<0.05$ for two tails.

\section{Results}

\section{Descriptive analysis}

Figure 1 illustrated that the prevalence of allergic diseases was higher in boys than in girls. There were $7.4 \%, 17.5 \%$, and $13.4 \%$ of participants has been diagnosed with asthma, allergic rhinitis, and eczema, respectively. Table 1 summarized the distribution of age, gender, socio-economic status, maternal and perinatal characteristics as well as lifestyles of three patient groups. Generally, children who are male, living in a high-income family, having a mother or/and father of high educational level, been given mixed or/and artificial feeding patterns, and of high maternal and/or paternal age at delivery were associated with an increased prevalence of three allergic diseases. Besides, adolescents who are overweight 

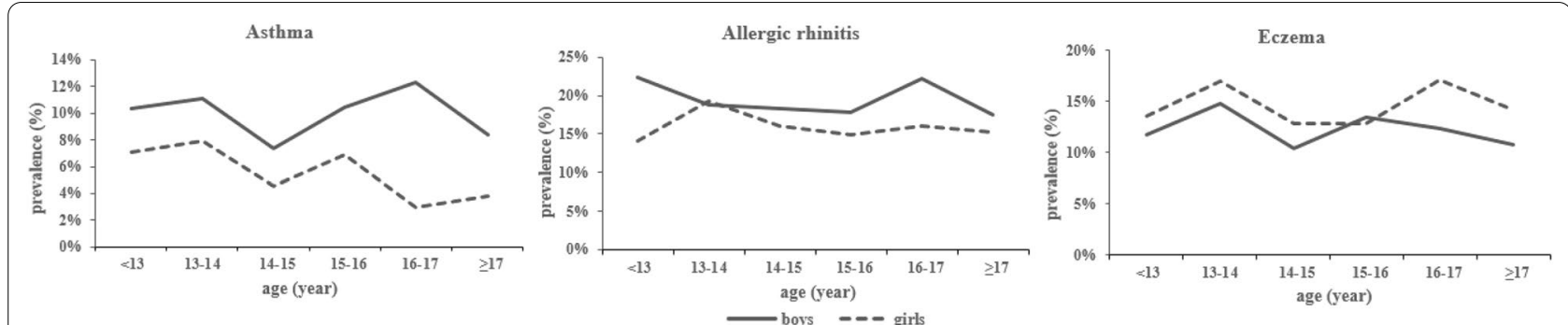

Fig. 1 Age and gender-specific prevalence of childhood respiratory allergies

and get drinks were more likely to develop asthma and allergic rhinitis. Post-term delivery was associated with an increased risk of asthma $(p=0.02)$. Maternal smoking during pregnancy was associated with increased odds of asthma $(p=0.05)$ and allergic rhinitis $(p=0.04)$, and maternal poor sleep during pregnancy was shown to be associated with an increased risk of eczema $(p=0.002)$.

\section{Association between sleep features and allergic diseases}

Table 2 summarized all sleep characteristics and their crude relationships with three allergic diseases. For asthma, sleep-disordered breathing and sleep physiology were found to be influential factors after adjusting for multiple testing. Difficulty in maintaining sleep $\left(p=0.002, \quad p^{*}=0.008\right), \quad$ sleep-disordered breathing $\left(p<0.001, p^{*}<0.001\right)$, poor sleep physiology $(p=0.001$, $\left.p^{*}=0.008\right)$ and sleep emotion $\left(p=0.002, p^{*}=0.008\right)$ were all associated with an increased risk of allergic rhinitis, even after adjusting for multiple comparisons. Except for difficulty in falling asleep $\left(p=0.09, p^{*}=0.18\right)$, all other sleep parameters on sleep problems and sleep hygiene were found to be associated with higher risks of eczema in the univariate regression models. When it comes to sleep duration, only sleep $<8 \mathrm{~h}$ on weekend was associated with an increased risk of eczema $(p=0.03$, $\left.p^{*}=0.04\right)$.

As shown in Table 3, sleep duration on weekdays and weekends was not associated with risks of asthma and allergic rhinitis. Nighttime sleep $<8$ h on weekends was associated with higher odds of eczema in the final adjusted model (adjusted OR: 1.40, 95\% CI 1.00-1.97, $p=0.05)$, however, the significance disappeared after correcting for multiple comparisons $(p=0.07)$. Table 4 showed associations between six subscales of sleep problems with allergic diseases. Difficulty in falling asleep (adjusted OR: 1.26, 95\% CI 1.03-1.55, $p<0.001$ ) and disorders of arousal (adjusted OR: 1.55, 95\% CI 1.24-1.92, $p<0.001$ ) were associated with an increased risk of eczema. Difficulties in maintaining sleep and reinitializing sleep were also significantly associated with allergic rhinitis and eczema in the final model. Meanwhile, sleep-disordered breathing was associated with $79 \%$ (95\% CI 1.25-2.55, $p=0.001), 95 \%$ (95\% CI 1.52-2.49, $p<0.001)$ and 63\% (95\% CI 1.23-2.16, $p=0.001$ ) higher odds of asthma, allergic rhinitis, and eczema, respectively. Table 5 showed that poor sleep psychology and sleep environment were associated with a predisposition to developing all three allergic diseases in final adjusted models. Negative sleep cognition and poor sleep stability presented a significant association with higher odds of asthma and eczema. Negative sleep emotion was significantly associated with higher risks of allergic rhinitis (adjusted OR $=1.36,95 \%$ CI 1.09 $1.70, p=0.006$ ) and eczema (adjusted $\mathrm{OR}=1.71,95 \%$ CI $1.36-2.16, p<0.001)$. Since significant correlations were identified between sleep parameters as well as between atopic diseases (Additional file 1: Table S1, S2), multiple testing corrections were performed. And most of the significance remained after correcting for multiple comparisons.

\section{Discussion}

The study assessed the association of sleep duration, sleep problems, and sleep hygiene with three allergic diseases, including asthma, allergic rhinitis, and eczema among adolescents. The study covered a full-spectrum of sleep features, and sleep duration was classified into weekends and weekdays. Variables on sleep problems and sleep hygiene were collected through standardized and validated questionnaires. We found that sleep problems and sleep hygiene, especially sleep-disordered breathing, sleep physiology, and sleep environment, were essentially connected with all atopic diseases in adolescents. These findings provided a comprehensive insight into the relationship between sleep and allergic diseases. Given that adolescence is a critical period for long-term control of atopic episodes, particular emphasis should be placed on sleep problems and sleep hygiene in the management of allergic diseases. 
Table 1 Characteristics of participants with asthma, allergic rhinitis and eczema, column \%

\begin{tabular}{|c|c|c|c|c|c|c|c|c|c|}
\hline \multirow[t]{2}{*}{ Characteristics (N) } & \multicolumn{3}{|c|}{$\begin{array}{l}\text { Asthma } \\
(\mathrm{N}=367)\end{array}$} & \multicolumn{3}{|c|}{$\begin{array}{l}\text { Allergic rhinitis } \\
(\mathrm{N}=861)\end{array}$} & \multicolumn{3}{|c|}{$\begin{array}{l}\text { Eczema } \\
(\mathrm{N}=661)\end{array}$} \\
\hline & $\%$ & \multicolumn{2}{|l|}{ OR $(95 \% \mathrm{Cl})$} & $\%$ & \multicolumn{2}{|l|}{ OR $(95 \% \mathrm{Cl})$} & $\%$ & \multicolumn{2}{|l|}{ OR $(95 \% \mathrm{Cl})$} \\
\hline \multicolumn{10}{|l|}{ Demographic characteristics } \\
\hline \multicolumn{10}{|l|}{ Age (years) } \\
\hline$<13(649)$ & 15.3 & $0.69(0.48-0.98)$ & 0.04 & 13.7 & $0.88(0.69-1.13)$ & 0.33 & 12.4 & $1.00(0.75-1.32)$ & 0.98 \\
\hline $13-14(694)$ & 18.0 & $0.88(0.59-1.31)$ & 0.53 & 15.4 & $1.07(0.81-1.41)$ & 0.65 & 16.7 & $1.19(0.87-1.63)$ & 0.28 \\
\hline 14-15 (707) & 11.5 & $1.00(0.68-1.47)$ & 0.99 & 14.1 & $0.91(0.68-1.21)$ & 0.45 & 12.6 & $1.04(0.75-1.43)$ & 0.82 \\
\hline $15-16(715)$ & 16.9 & $0.68(0.45-1.04)$ & 0.07 & 13.7 & $0.94(0.71-1.25)$ & 0.66 & 14.3 & $0.92(0.66-1.28)$ & 0.61 \\
\hline $16-17(695)$ & 14.2 & $1.17(0.80-1.71)$ & 0.41 & 15.4 & $1.12(0.85-1.49)$ & 0.42 & 15.6 & $1.34(0.98-1.83)$ & 0.07 \\
\hline$\geq 17(1450)$ & 24.0 & Ref. & & 27.7 & Ref. & & 28.4 & Ref. & \\
\hline \multicolumn{10}{|l|}{ Gender } \\
\hline Boy (2422) & 64.4 & $1.92(1.53-2.40)$ & $<0.001$ & 54.0 & $1.25(1.07-1.45)$ & 0.004 & 44.4 & $0.85(0.72-1.00)$ & 0.05 \\
\hline Girl (2495) & 35.6 & Ref. & & 46.0 & Ref. & & 55.6 & Ref. & \\
\hline \multicolumn{10}{|c|}{ Household income (RMB /person/month) } \\
\hline$>3000 \mathrm{RMB}^{\mathrm{b}}(2100)$ & 53 & $1.60(1.28-1.99)$ & $<0.001$ & 51.3 & $1.50(1.28-1.74)$ & $<0.001$ & 50.5 & $1.45(1.22-1.71)$ & $<0.001$ \\
\hline$\leqq 3000 \mathrm{RMB}^{\mathrm{b}}(2694)$ & 47 & Ref. & & 48.7 & Ref. & & 49.5 & Ref. & \\
\hline \multicolumn{10}{|l|}{ Family structure } \\
\hline Single parent family (269) & 6.2 & $1.23(0.77-1.97)$ & 0.38 & 6.4 & $1.22(0.89-1.69)$ & 0.22 & 6.0 & $1.18(0.82-1.70)$ & 0.37 \\
\hline Nuclear family (2632) & 51.7 & Ref. & & 53.8 & Ref. & & 52.2 & Ref. & \\
\hline Extended family (1941) & 42.1 & $1.11(0.89-1.39)$ & 0.36 & 39.8 & $1.01(0.86-1.18)$ & 0.91 & 41.8 & $1.09(0.92-1.30)$ & 0.33 \\
\hline \multicolumn{10}{|l|}{ Mother's educational levels } \\
\hline College and above (1713) & 47.4 & $2.71(1.97-3.73)$ & $<0.001$ & 46.3 & $2.68(2.15-3.35)$ & $<0.001$ & 44.2 & $2.32(1.82-2.95)$ & $<0.001$ \\
\hline High school (1674) & 37.0 & $2.01(1.44-2.79)$ & $<0.001$ & 38.3 & $2.11(1.68-2.64)$ & $<0.001$ & 38.7 & $1.93(1.51-2.46)$ & $<0.001$ \\
\hline Middle school and below $(1,218)$ & 15.6 & Ref. & & 15.4 & Ref. & & 17.0 & Ref. & \\
\hline \multicolumn{10}{|l|}{ Father's educational levels } \\
\hline College and above (1980) & 51.9 & $2.90(2.03-4.15)$ & $<0.001$ & 52.1 & $2.62(2.07-3.30)$ & $<0.001$ & 50.6 & $2.30(1.79-2.96)$ & $<0.001$ \\
\hline High school (1731) & 36.8 & $2.15(1.49-3.11)$ & $<0.001$ & 35.3 & $1.85(1.45-2.35)$ & $<0.001$ & 35.4 & $1.68(1.29-2.18)$ & $<0.001$ \\
\hline Middle school and below (1015) & 11.3 & Ref. & & 12.6 & Ref. & & 13.9 & Ref. & \\
\hline \multicolumn{10}{|c|}{ Obstetrics and parental health characteristics } \\
\hline \multicolumn{10}{|c|}{ Delivery mode } \\
\hline Premature delivery (504) & 10.6 & $1.05(0.73-1.51)$ & 0.79 & 11.5 & $1.12(0.88-1.43)$ & 0.36 & 12.7 & $1.25(0.96-1.62)$ & 0.10 \\
\hline Post-term delivery (297) & 9.2 & $1.59(1.07-2.35)$ & 0.02 & 7.0 & $1.19(0.87-1.67)$ & 0.27 & 6.5 & $1.12(0.79-1.59)$ & 0.53 \\
\hline Term delivery (3858) & 80.2 & Ref. & & 81.5 & Ref. & & 80.7 & Ref. & \\
\hline \multicolumn{10}{|l|}{ Feeding pattern } \\
\hline Mixed feeding (994) & 23.1 & $1.34(1.02-1.76)$ & 0.04 & 25.7 & $1.51(1.26-1.82)$ & $<0.001$ & 26.7 & $1.58(1.29-1.94)$ & $<0.001$ \\
\hline Artificial feeding (681) & 19.1 & $1.59(1.18-2.14)$ & 0.002 & 17.4 & $1.48(1.19-1.83)$ & $<0.001$ & 17.0 & $1.45(1.14-1.84)$ & 0.002 \\
\hline Breastfeeding (2991) & 57.8 & Ref. & & 56.8 & Ref. & & 56.3 & Ref. & \\
\hline \multicolumn{10}{|l|}{ Maternal smoking during gestation } \\
\hline Yes $(40)$ & 1.7 & $2.48(1.00-6.13)$ & 0.05 & 1.4 & $2.12(1.05-4.27)$ & 0.04 & 0.8 & $1.16(0.44-3.05)$ & 0.77 \\
\hline No (4756) & 98.3 & Ref. & & 98.6 & Ref. & & 99.2 & Ref. & \\
\hline \multicolumn{10}{|l|}{ Maternal drinking during gestation } \\
\hline Drinking (71) & 1.7 & $1.18(0.50-2.78)$ & 0.70 & 1.9 & $1.35(0.76-2.39)$ & 0.30 & 1.3 & $0.88(0.42-1.88)$ & 0.75 \\
\hline Non-drinking (4721) & 98.3 & Ref. & & 98.1 & Ref. & & 98.8 & Ref. & \\
\hline \multicolumn{10}{|c|}{ Mother's sleep condition during gestation } \\
\hline Fair (1354) & 27.2 & $0.98(0.78-1.23)$ & 0.85 & 30.3 & $1.12(0.96-1.30)$ & 0.16 & 34.8 & $1.31(1.11-1.55)$ & 0.002 \\
\hline Good (3227) & 72.8 & Ref. & & 69.7 & Ref. & & 65.2 & Ref. & \\
\hline Mother's age at delivery(year) & & & & & & & & & \\
\hline$\geq 30(644)$ & 19.5 & $1.99(1.45-2.73)$ & $<0.001$ & 17.2 & $1.60(1.27-2.00)$ & $<0.001$ & 17.2 & $1.58(1.23-2.04)$ & $<0.001$ \\
\hline $25-29(1870)$ & 47.5 & $1.64(1.28-2.10)$ & $<0.001$ & 45.5 & $1.43(1.21-1.69)$ & $<0.001$ & 45.9 & $1.43(1.18-1.73)$ & $<0.001$ \\
\hline
\end{tabular}


Table 1 (continued)

\begin{tabular}{|c|c|c|c|c|c|c|c|c|c|}
\hline \multirow[t]{2}{*}{ Characteristics (N) } & \multicolumn{3}{|c|}{$\begin{array}{l}\text { Asthma } \\
(\mathrm{N}=367)\end{array}$} & \multicolumn{3}{|c|}{$\begin{array}{l}\text { Allergic rhinitis } \\
(\mathrm{N}=861)\end{array}$} & \multicolumn{3}{|c|}{$\begin{array}{l}\text { Eczema } \\
(N=661)\end{array}$} \\
\hline & $\%$ & OR $(95 \% \mathrm{Cl})$ & & $\%$ & OR $(95 \% \mathrm{Cl})$ & & $\%$ & OR $(95 \% \mathrm{Cl})$ & \\
\hline$\leq 24(2057)$ & 33.0 & Ref. & & 37.3 & Ref. & & 36.9 & Ref. & \\
\hline \multicolumn{10}{|l|}{ Father's age at delivery } \\
\hline$\geq 35(486)$ & 14.4 & $2.16(1.56-2.98)$ & $<0.001$ & 11.6 & $1.69(1.34-2.12)$ & $<0.001$ & 13.3 & $1.71(1.32-2.21)$ & $<0.001$ \\
\hline $25-34(2971)$ & 76.4 & $1.79(1.39-2.30)$ & $<0.001$ & 74.3 & $1.52(1.28-1.81)$ & $<0.001$ & 69.7 & $1.55(1.28-1.87)$ & $<0.001$ \\
\hline$\leq 24(1037)$ & 9.2 & Ref. & & 14.1 & Ref. & & 13.2 & Ref. & \\
\hline \multicolumn{10}{|c|}{ Biological chronic health problems and activity routine behaviors } \\
\hline \multicolumn{10}{|c|}{ Overweight/obesity } \\
\hline Yes (659) & 19.4 & $1.59(1.20-2.11)$ & 0.001 & 17.1 & $1.36(1.10-1.67)$ & 0.004 & 15.5 & $1.21(0.95-1.54)$ & 0.12 \\
\hline No (4009) & 80.6 & Ref. & & 82.9 & Ref. & & 84.5 & Ref. & \\
\hline \multicolumn{10}{|l|}{ Smoking exposure } \\
\hline Yes (1313) & 30.5 & $1.23(0.97-1.56)$ & 0.08 & 29.3 & $1.17(0.99-1.38)$ & 0.07 & 29.3 & $1.16(0.97-1.40)$ & 0.11 \\
\hline No (3522) & 69.5 & Ref. & & 70.7 & Ref. & & 70.7 & Ref. & \\
\hline \multicolumn{10}{|l|}{ Drinking status } \\
\hline Current drinking (381) & 11.7 & $1.73(1.22-2.43)$ & 0.002 & 10.0 & $1.45(1.12-1.87)$ & 0.005 & 8.3 & $1.18(0.87-1.60)$ & 0.29 \\
\hline Non-drinking (4540) & 88.3 & Ref. & & 90.0 & Ref. & & 91.7 & Ref. & \\
\hline \multicolumn{10}{|l|}{ Physical activity during weekdays } \\
\hline Physically active time < 1 h/day (4049) & 68.7 & $0.95(0.71-1.26)$ & 0.71 & 67.8 & $1.02(0.84-1.25)$ & 0.84 & 70.3 & $0.95(0.76-1.18)$ & 0.62 \\
\hline Physically active time $\geq 1$ h/day (843) & 31.3 & Ref. & & 32.2 & Ref. & & 29.7 & Ref. & \\
\hline \multicolumn{10}{|l|}{ Physical activity during weekends } \\
\hline Physically active time < 1 h/day (3421) & 81.9 & $0.94(0.74-1.19)$ & 0.60 & 83.0 & $0.90(0.77-1.06)$ & 0.20 & 81.9 & $1.01(0.84-1.22)$ & 0.90 \\
\hline Physically active time $\geq 1$ h/day (1470) & 18.1 & Ref. & & 17.0 & Ref. & & 18.1 & Ref. & \\
\hline
\end{tabular}

a Statistically significant results $(p<0.05)$ are in italics

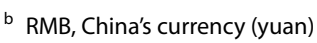

\section{Sleep duration with atopic adolescents}

In our study, short sleep duration was not associated with childhood allergic diseases, which was not exactly consistent with some of the previous findings [27-29]. In a Korean study aiming at adolescents aged $12-18$, the odds ratio of allergic rhinitis increased in both genders when sleep duration was $<7 \mathrm{~h}$ [27]. A case-control study conducted in Australia, with an enrollment of children aged 5-17 years old, found that male asthmatic children have a significantly shorter sleep duration than controls $(425.9 \pm 5.4 \mathrm{~min}$ vs $441.85 \pm 5.4 \mathrm{~min})$, but the difference was not revealed in females [28]. However, a study carried out in the USA obtained no significant difference in total sleep duration between asthmatic and non-asthmatic adolescents on weekdays and weekends [29]. Analogously, we also analyzed weekday and weekend sleep duration separately. Since Chinese high school students were always with lumbersome academic burden, the sleep pattern could vary from weekdays to weekends, as such, it should not be lumped together. This could explain that our results were, in some aspects, different from those in other countries.

\section{Sleep problems with atopic adolescents}

All six subscales of sleep problems were associated with increased odds of eczema among adolescents; and meanwhile, difficulty in maintaining sleep and reinitializing sleep presented to be related to significant higher odds of allergic rhinitis. Our study found that sleep-disordered breathing was associated with increased risks of all three allergic diseases, which was accordant with 12 out of 18 articles' results on allergic rhinitis reviewed in 2013 [30]. A birth cohort study of 566 toddlers, also indicated that sleep disorder was a potential risk factor for allergic diseases [31]. A case-control study found that compared to controls, participants (6-16-year-old) with eczema had more disturbed sleep with significantly higher scores on initiating and maintaining sleep disorders, excessive daytime sleepiness, and total sleep disturbance [32]. Within same population, children with eczema had worse sleep quality [33]. Similarly, another research in the US suggested that children with eczema had nearly $50 \%$ higher odds of reporting sleep-quality disturbances [34]. However, two other cohort studies obtained 


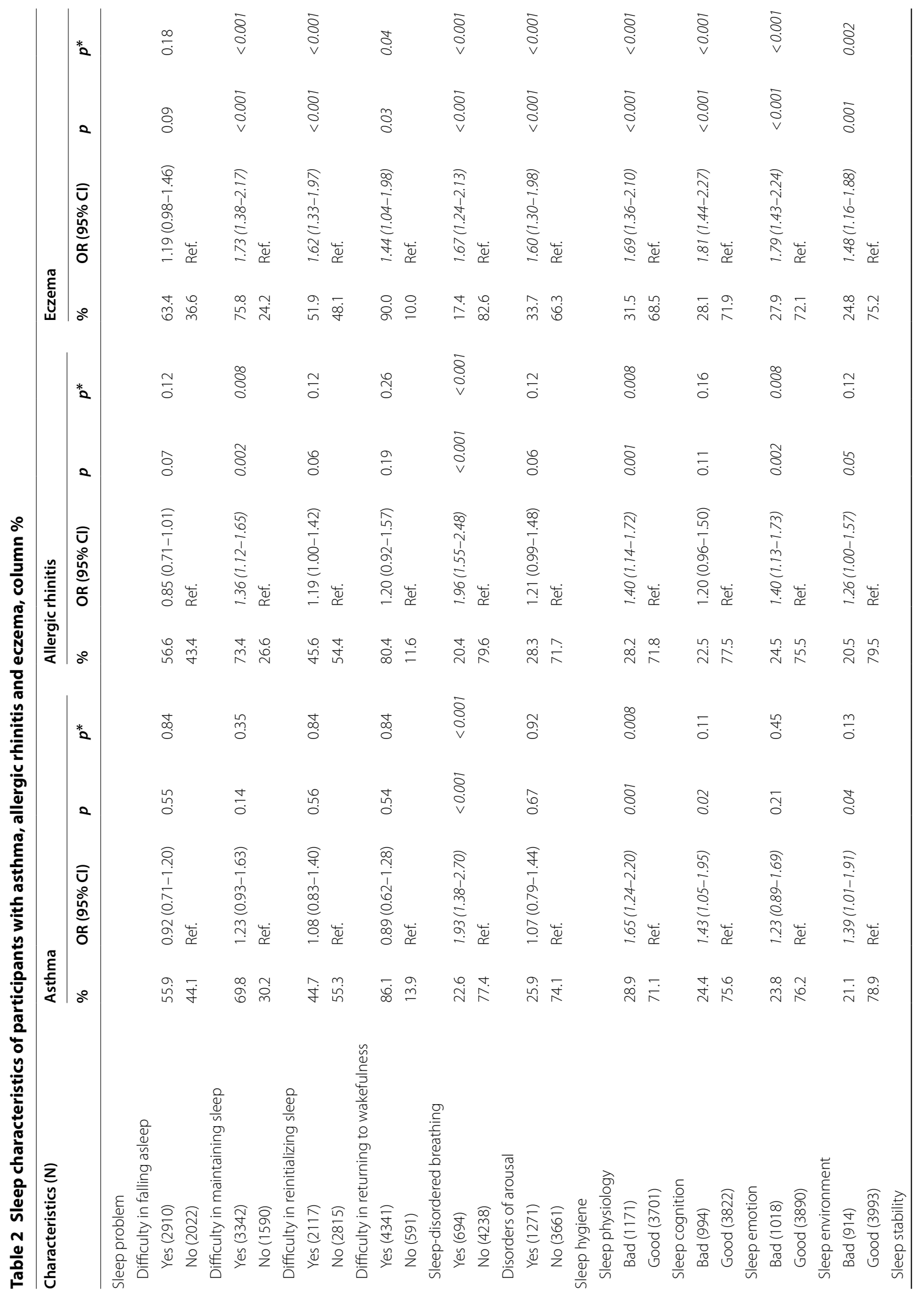




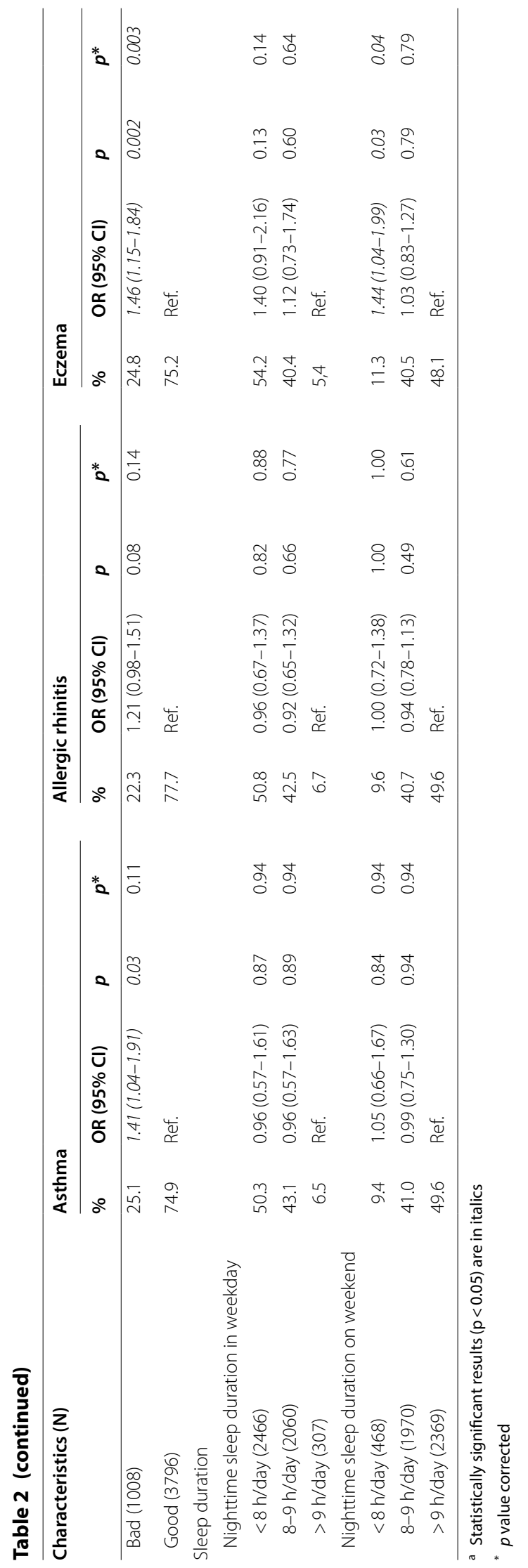


Table 3 Association of sleep duration with asthma, allergic rhinitis, eczema

\begin{tabular}{|c|c|c|c|c|c|c|c|c|c|c|c|c|}
\hline & \multicolumn{12}{|c|}{ Sleep duration, odds ratio ( $95 \%$ confidence interval) } \\
\hline & \multicolumn{6}{|c|}{ Nighttime sleep duration in weekday } & \multicolumn{6}{|c|}{ Nighttime sleep duration on weekends } \\
\hline & $<8$ vs. $\geq 9$ h/day & $p$ & $p^{*}$ & $8-9$ vs. $\geq 9$ h/day & $p$ & $p^{*}$ & $<8$ vs. $\geq 9$ h/day & $p$ & $p^{*}$ & $8-9$ vs. $\geq 9$ h/day & $p$ & $p^{*}$ \\
\hline \multicolumn{13}{|l|}{ Asthma } \\
\hline Adjusted model 1 & $1.19(0.67-2.12)$ & 0.55 & 0.83 & $0.99(0.58-1.70)$ & 0.98 & 0.98 & $1.01(0.63-1.64)$ & 0.96 & 0.98 & $1.02(0.77-1.35)$ & 0.91 & 0.98 \\
\hline Adjusted model 2 & $1.22(0.68-2.17)$ & 0.51 & 0.77 & $1.03(0.60-1.78)$ & 0.91 & 0.96 & $1.03(0.64-1.68)$ & 0.90 & 0.96 & $1.04(0.78-1.38)$ & 0.81 & 0.96 \\
\hline Adjusted model 3 & $1.19(0.66-2.13)$ & 0.57 & 1.00 & $1.05(0.61-1.80)$ & 0.88 & 1.00 & $0.97(0.60-1.59)$ & 0.91 & 1.00 & $1.04(0.78-1.38)$ & 0.80 & 1.00 \\
\hline \multicolumn{13}{|l|}{ Allergic rhinitis } \\
\hline Adjusted model1 & $0.92(0.62-1.37)$ & 0.69 & 0.74 & $0.87(0.60-1.26)$ & 0.46 & 0.53 & $0.95(0.69-1.33)$ & 0.78 & 0.78 & $0.93(0.76-1.12)$ & 0.44 & 0.53 \\
\hline Adjusted model 2 & $0.92(0.62-1.37)$ & 0.69 & 0.74 & $0.88(0.61-1.28)$ & 0.51 & 0.58 & $0.96(0.68-1.34)$ & 0.79 & 0.79 & $0.93(0.76-1.13)$ & 0.46 & 0.57 \\
\hline Adjusted model 3 & $0.91(0.61-1.36)$ & 0.64 & 0.69 & $0.88(0.61-1.28)$ & 0.50 & 0.58 & $0.94(0.67-1.31)$ & 0.70 & 0.70 & $0.93(0.76-1.13)$ & 0.45 & 0.56 \\
\hline \multicolumn{13}{|l|}{ Eczema } \\
\hline Adjusted model1 & $1.49(0.93-2.40)$ & 0.10 & 0.11 & $1.17(0.74-1.83)$ & 0.50 & 0.54 & $1.40(1.00-1.95)$ & 0.05 & 0.07 & $1.03(0.83-1.28)$ & 0.70 & 0.77 \\
\hline Adjusted model 2 & $1.45(0.90-2.34)$ & 0.12 & 0.14 & $1.16(0.74-1.82)$ & 0.53 & 0.56 & $1.44(1.02-2.02)$ & 0.04 & 0.05 & $1.05(0.85-1.31)$ & 0.65 & 0.65 \\
\hline Adjusted model 3 & $1.45(0.90-2.34)$ & 0.13 & 0.15 & $1.16(0.74-1.82)$ & 0.52 & 0.56 & $1.40(1.00-1.97)$ & 0.05 & 0.07 & $1.05(0.85-1.31)$ & 0.65 & 0.65 \\
\hline
\end{tabular}

Adjusted model 1 was adjusted for demographic characteristics, family structure and socioeconomic status

Adjusted model 2 was further adjusted for conditions of gestation, delivery and feeding besides the covariates in adjusted model 1

Adjusted model 3 was further adjusted for health problems, daily activity and behavior routine besides the covariates in adjusted model 2

* $p$ value corrected

a Statistically significant results $(p<0.05)$ are in italics

significant results, not in eczema, but in asthma and allergic rhinitis $[16,17]$.

\section{Sleep hygiene with atopic adolescents}

For sleep hygiene, adolescents with allergic diseases have more negative bedtime cognitions, feeling worried and uncomfortable while attempting to fall asleep. A review illustrated that children with atopic disease had more nocturnal symptoms, and they might have poorer sleep hygiene for fear of the nocturnal episodes and can be more likely to experience physical arousal [25]. A study which has investigated 298 adolescents found that adolescents with severe asthma were more likely to sleep on someone else's bed, such as a parent's bed, sibling's bed, and even couch, and had more negative bedtime cognition that may interfere with sleep onset [29]. A study involving 549 college students suggested that, after the 8 weeks of education on sleep hygiene, participants tended to maintain more regular sleep schedules, woke up earlier during the week, took fewer naps, and stopped using electronic devices at bedtime [35]. This suggested that sleep hygiene education can benefit adolescents with allergic diseases feasibly and inexpensively.

\section{Bidirectional mechanisms between sleep and allergic diseases}

The causal relationship between sleep and allergic diseases can vary by study, that is, the chicken-and-egg situation. Dating back to 1992, the first study reported the relationship between habitual snoring and exerciseinduced asthma [36]. Since then, several studies have attempted to explain the potential mechanism between sleep and allergic diseases [37-42].

Since cortisol secretion, cytokine production, and immune function were all supposed to be regulated by the circadian rhythm [37]. Night-induced antiinflammatory cytokines such as IL-4 and IL-10 were reported to inhibit sleep, while pro-inflammatory cytokines such as IL-1 $\beta$, IL-2, TNF, IFN- $\gamma$ and IL-6 were suggested to promote sleep [38]. On the contrary, sleep also has an impact on the immune function. Sleep loss altered the immune response to lipopolysaccharide stimulations and susceptibility to infections [39-41]. In an animal model, sleep deprivation resulted in increased levels of pro-inflammatory cytokines such as IL-1 $\beta$, IL-6, and IL-12, and a decreased levels of anti-inflammatory cytokines such as IL-10, which normalized after a 48-h sleep rebound [42]. Studies have shown that the level of IL-1 $\beta$, IL-6, IL-17, and high sensitivity C-reactive protein increased after chronic partial sleep deprivation, and IL-1 $\beta$, IL-6, TNF- $\alpha$ levels increased after acute sleep deprivation [40]. Through the variation of cytokine levels, the relationship between sleep disorders and allergic diseases can be bidirectional.

\section{Limitations}

A number of limitations should be noticed. Firstly, our cross-sectional study was incapable of explaining the 


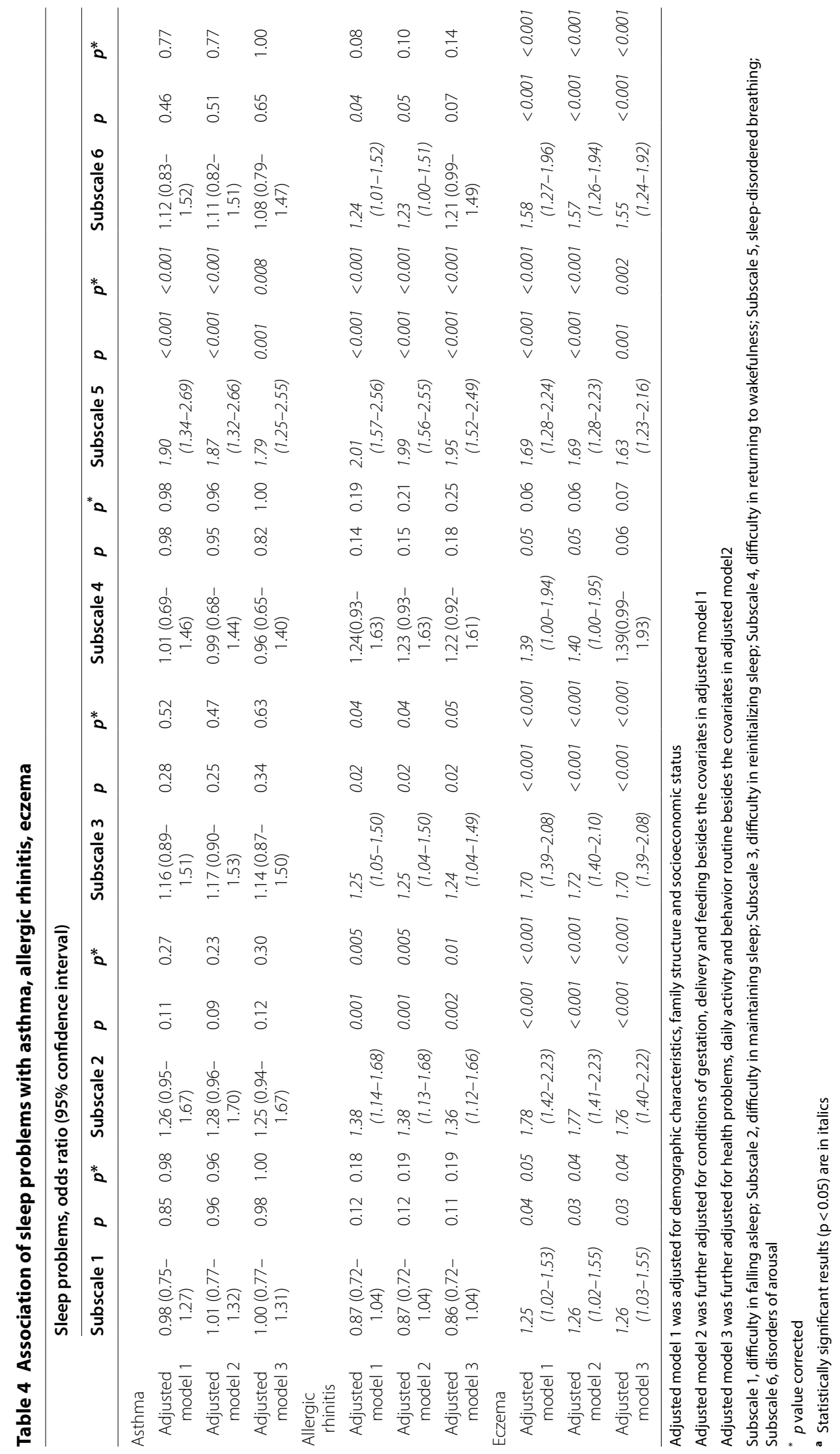




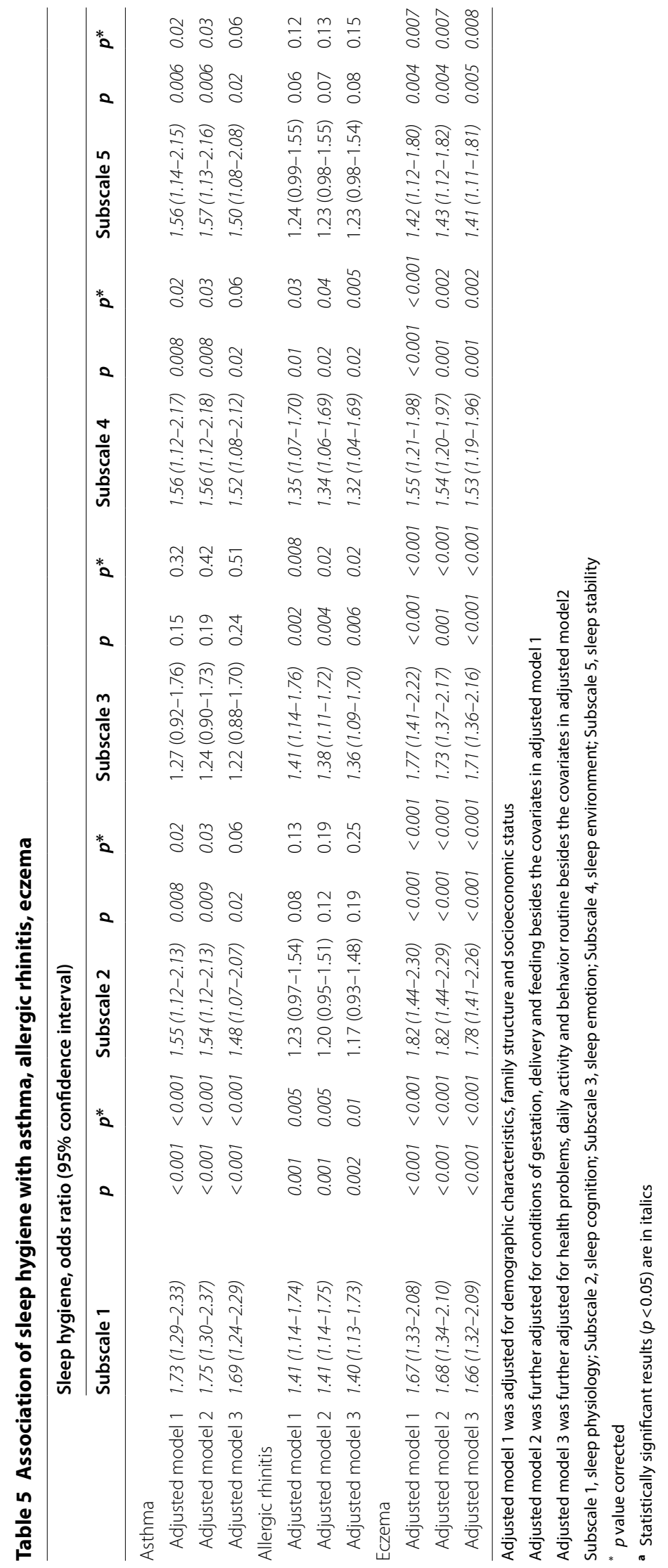


causal links. The relationship between sleep and allergic disease could be bidirectional, and both are worth further exploration. Additionally, although our study included a large number of confounding factors of the three allergic diseases, information on drug usages were unavailable [43], which should be taken into consideration in future researches. Moreover, the results we present were according to self-reported data, however, atopic diseases were determined by the physician's diagnosis, and sleep characteristics were based on validated questionnaires. Finally, the results were backed up by data from 10 years ago. Although there has been growing evidence recently, indicating that sleep can play a role in immune regulation, population-based study is largely lacking. Given that our study is aimed to explore the relationship between sleep characteristics and the risk of atopic diseases, rather than describing sleep characteristics and prevalence of the atopic disease, the findings could still provide some implications for further investigations. Future researches can build on our study with more biophysical and biochemical parameters of atopic diseases and more objective measurements of sleep.

\section{Conclusions}

This study is the first to explore the relationship between the full-spectrum sleep features of adolescents, including sleep duration, sleep problem and sleep hygiene, and the three core allergic diseases herein asthma, allergic rhinitis, and eczema. Generally, sleep-disordered breathing, poor sleep physiology, and non-optimal environment were associated with increased risks of all three allergic diseases. This finding provides a new perspective for that sleep may be a modifiable risk factor in the management of the allergic diseases. Regular screening and specific treatment for sleep issues are supposed to be taken into the prevention strategies of allergic diseases.

\section{Supplementary Information}

The online version contains supplementary material available at https://doi. org/10.1186/s13223-021-00516-7.

Additional file 1: Table S1. Correlation analysis of sleep parameters. Table S2 Correlation analysis of allergic diseases.

\section{Abbreviations}

OR: Odds ratio; Cl: Confidence interval; ASDQ: Adolescent sleep disturbance questionnaire; ASHS: Adolescent sleep hygiene scale; M-ASHS: Modified Chinese version of adolescent sleep hygiene scale; IL: Interleukin; TNF:Tumor necrosis factor; IFN- $\gamma$ : Interferon- $\gamma$.

\section{Acknowledgements}

The authors would like to thank Shilu Tong for his helpful review and comments on the manuscript.

\section{Authors' contributions}

Study concept and design: SL. Statistical analysis: YC and QY. Drafting of the manuscript: YC and QY. Critical revision of the manuscript: SL and YC. Survey and data collection: KZ, ZW, and XS. All authors read and approved the final manuscript.

\section{Funding}

The study was funded by grants from National Natural Science Foundation of China $(81673183,81874266)$, key project from Shanghai Municipal Science and Technology Commission (18411951600), the Science and Technology Funds from Pudong New Area, Shanghai (PKJ2017-Y01).

\section{Availability of data and materials}

The datasets used and analysed during the current study are available from the corresponding author on reasonable request.

\section{Ethics approval and consent to participate}

The ethical application and the consent procedure of the study were approved by the Ministry of Education of People's Republic of China and Ethics Committee of Shanghai Jiao Tong University School of Medicine.

\section{Consent for publication}

Not applicable.

\section{Competing interests}

The authors declare that they have no competing interests.

\section{Author details}

${ }^{1}$ School of Public Health, Shanghai Jiao Tong University School of Medicine, 227 South Chongqing Road, Huangpu District, Shanghai 200025, China. ${ }^{2}$ MOE-Shanghai Key Laboratory of Children's Environmental Health, Shanghai Jiao Tong University School of Medicine, Shanghai, China. ${ }^{3}$ Shanghai Academy of Educational Science, Shanghai, China.

Received: 11 December 2019 Accepted: 21 January 2021

Published online: 22 February 2021

\section{References}

1. Worldwide variation in prevalence of symptoms of asthma, allergic rhinoconjunctivitis, and atopic eczema: ISAAC. The International Study of Asthma and Allergies in Childhood (ISAAC) Steering Committee. Lancet 1998:351:1225-1232.

2. Zhang Y, Li B, Huang C, et al. Investigation of asthma and other allergic diseases in children in 10 cities of China. Kexue Tongbao. 2013;58:2504-12.

3. Platts-Mills TA. The allergy epidemics: 1870-2010. J Allergy Clin Immunol. 2015;136:3-13.

4. Vinding GR, Zarchi K, Ibler KS, et al. Is adult atopic eczema more common than we think? A population-based study in Danish adults. Acta Derm Venereol. 2014;94:480-2.

5. Mortz CG, Andersen KE, Dellgren C, et al. Atopic dermatitis from adolescence to adulthood in the TOACS cohort: prevalence, persistence and comorbidities. Allergy. 2015;70:836-45.

6. Tan DJ, Walters EH, Perret JL, et al. Age-of-asthma onset as a determinant of different asthma phenotypes in adults: a systematic review and metaanalysis of the literature. Expert Rev Respir Med. 2015;9:109-23.

7. Sandstrom MH, Faergemann J. Prognosis and prognostic factors in adult patients with atopic dermatitis: a long-term follow-up questionnaire study. Br J Dermatol. 2004;150:103-10.

8. Bartel KA, Gradisar M, Williamson P. Protective and risk factors for adolescent sleep: a meta-analytic review. Sleep Med Rev. 2015;21:72-85.

9. Williams JA, Zimmerman FJ, Bell JF. Norms and trends of sleep time among US children and adolescents. JAMA Pediatr. 2013;167:55-60.

10. Knutson KL, Spiegel K, Penev P, et al. The metabolic consequences of sleep deprivation. Sleep Med Rev. 2007;11:163-78.

11. Godinho-Silva C, Domingues RG, Rendas M, et al. Light-entrained and brain-tuned circadian circuits regulate ILC3s and gut homeostasis. Nature. 2019;574:254-8. 
12. Bryant PA, Trinder J, Curtis N. Sick and tired: does sleep have a vital role in the immune system? Nat Rev Immunol. 2004;4:457-67.

13. Fleming WE, Ferouz-Colborn A, Samoszuk MK, et al. Blood biomarkers of endocrine, immune, inflammatory, and metabolic systems in obstructive sleep apnea. Clin Biochem. 2016;49:854-61.

14. Chang YS, Chiang BL. Sleep disorders and atopic dermatitis: a 2-way street? J Allergy Clin Immunol. 2018;142:1033-40.

15. Zhang S, Liu X, Kim JS, et al. Association between short sleep duration and the risk of sensitization to food and aero allergens in rural Chinese adolescents. Clin Exp Allergy. 2011;41:547-55.

16. Jernelov S, Lekander M, Almqvist C, et al. Development of atopic disease and disturbed sleep in childhood and adolescence - a longitudinal population-based study. Clin Exp Allergy. 2013;43:552-9.

17. Ross KR, Storfer-Isser A, Hart MA, et al. Sleep-disordered breathing is associated with asthma severity in children. J Pediatr. 2012;160:736-42.

18. Wang Y, Chen Z, Guo F, et al. Sleep patterns and their association with depression and behavior problems among Chinese adolescents in different grades. Psych J. 2017;6:253-62.

19. Chen T, Wu Z, Shen Z, et al. Sleep duration in Chinese adolescents: biological, environmental, and behavioral predictors. Sleep Med. 2014;15:1345-53.

20. YY. Rating scales for children's developmental behavior and mental health. House PsMP 2016;191-193.

21. Zhao K, Zhang J, Wu Z, et al. The relationship between insomnia symptoms and school performance among 4966 adolescents in Shanghai, China. Sleep Health. 2019;5:273-9.

22. Zhang J, Xu Z, Zhao K, et al. Sleep habits, sleep problems, sleep hygiene, and their associations with mental health problems among adolescents. J Am Psychiatr Nurses Assoc. 2018;24:223-34

23. Storfer-Isser A, Lebourgeois MK, Harsh J, et al. Psychometric properties of the adolescent sleep hygiene scale. J Sleep Res. 2013;22:707-16.

24. Meltzer LJ, Brimeyer C, Russell K, et al. The Children's report of sleep patterns: validity and reliability of the sleep hygiene index and sleep disturbance scale in adolescents. Sleep Med. 2014;15:1500-7.

25. Koinis-Mitchell D, Craig T, Esteban CA, et al. Sleep and allergic disease: a summary of the literature and future directions for research. J Allergy Clin Immunol. 2012;130:1275-81.

26. Benjamini Y, Hochberg Y. Controlling the false discovery rate: a practical and powerful approach to multiple testing. J R Stat Soc Ser B. 1995;57:289-300

27. Kwon JA, Lee M, Yoo KB, et al. Does the duration and time of sleep increase the risk of allergic rhinitis? Results of the 6-year nationwide Korea youth risk behavior web-based survey. PLoS ONE. 2013;8:e72507.
28. Jensen ME, Gibson PG, Collins CE, et al. Increased sleep latency and reduced sleep duration in children with asthma. Sleep Breath. 2013;17:281-7

29. Meltzer LJ, Ullrich M, Szefler SJ. Sleep duration, sleep hygiene, and insomnia in adolescents with asthma. J Allergy Clin Immunol Pract. 2014;2:562-9.

30. Lin SY, Melvin TA, Boss EF, et al. The association between allergic rhinitis and sleep-disordered breathing in children: a systematic review. Int Forum Allergy Rhinol. 2013;3:504-9.

31. Wang X, Gao X, Yang Q, et al. Sleep disorders and allergic diseases in Chinese toddlers. Sleep Med. 2017;37:174-9.

32. Camfferman D, Kennedy JD, Gold M, et al. Eczema, sleep, and behavior in children. J Clin Sleep Med. 2010;6:581-8.

33. Camfferman D, Kennedy JD, Gold M, et al. Sleep and neurocognitive functioning in children with eczema. Int J Psychophysiol. 2013;89:265-72.

34. Ramirez FD, Chen S, Langan SM, et al. Association of atopic dermatitis with sleep quality in children. JAMA Pediatr. 2019;173:e190025.

35. Hershner S, O'brien LM. The impact of a randomized sleep education intervention for college students. J Clin Sleep Med. 2018;14:337-47.

36. Teculescu DB, Caillier I, Perrin P, et al. Snoring in French preschool children. Pediatr Pulmonol. 1992;13:239-44.

37. Chang YS, Chiang BL. Mechanism of sleep disturbance in children with atopic dermatitis and the role of the circadian rhythm and melatonin. Int Jol Sci. 2016;17:462

38. Geiger SS, Fagundes CT, Siegel RM. Chrono-immunology: progress and challenges in understanding links between the circadian and immune systems. Immunology. 2015;146:349-58.

39. Lange T, Dimitrov S, Born J. Effects of sleep and circadian rhythm on the human immune system. Ann NY Acad Sci. 2010;1193:48-59.

40. Mullington JM, Simpson NS, Meier-Ewert HK, et al. Sleep loss and inflammation. Best Pract Res Clin Endocrinol Metab. 2010;24:775-84.

41. Besedovsky L, Lange T, Born J. Sleep and immune function. Pflugers Arch. 2012:463:121-37.

42. Hirotsu C, Rydlewski M, Araujo MS, et al. Sleep loss and cytokines levels in an experimental model of psoriasis. PLoS ONE. 2012;7:e51183.

43. Amberbir A, Medhin G, Hanlon C, et al. Effects of early life paracetamol use on the incidence of allergic disease and sensitization: 5 year follow-up of an Ethiopian birth cohort. PLOS ONE. 2014;9:e93869.

\section{Publisher's Note}

Springer Nature remains neutral with regard to jurisdictional claims in published maps and institutional affiliations.
Ready to submit your research? Choose BMC and benefit from:

- fast, convenient online submission

- thorough peer review by experienced researchers in your field

- rapid publication on acceptance

- support for research data, including large and complex data types

- gold Open Access which fosters wider collaboration and increased citations

- maximum visibility for your research: over $100 \mathrm{M}$ website views per year

At BMC, research is always in progress.

Learn more biomedcentral.com/submissions 